\title{
Reflection on the teaching of Cariology in Brazil
}

Fabio Correia Sampaio(a) Jonas Almeida Rodrigues ${ }^{(b)}$ Marcelo Bönecker(c) Sonia Groisman ${ }^{(d)}$

(a) Department of Clinical Dentistry, School of Dentistry, Univ Federal da Paraíba UFPB, João Pessoa, PB, Brazil; cariology curriculum group of ORCA (European Organisation for Caries Research).

(b) Department of Pediatric Dentistry, School of Dentistry, Univ Federal do Rio Grande do Sul - UFRGS, Porto Alegre, RS, Brazil.

(c) Department of Pediatric Dentistry, School of Dentistry, Univ de São Paulo - USP, São Paulo, SP, Brazil.

(d) Department of Preventive Dentistry, School of Dentistry, Univ Federal do Rio de Janeiro - UFRJ, Rio de Janeiro, RJ, Brazil; ORCA (European Organisation for Caries Research).

Acknowledgments: We are grateful to Dr. Saul M. Paiva and Dr. Andreas Schulte.

*All authors are members of the Alliance for a Cavity-Free Future - ACFF, Brazilian Chapter.
A lthough a reduction has been observed in the prevalence of dental caries among Brazilian children in the last 30 years, the prevalence among Brazilian adults and elderly people remains high. ${ }^{1}$ Dental caries is still responsible for significantly impacting the quality of life of many Brazilians. This situation implies that preventive and restorative therapy for caries will continue to be important issues for Brazilian dentists in the coming years.

The profile of practicing dentists has been described as traditional, positivist or surgical-operative, with a striking trend towards mechanism, biologism, individualism, specialization and exclusion of alternative practices, with a strong emphasis on dental procedure techniques. ${ }^{2}$

The traditional set of dentistry skills, characterized by a focus on technical, clinical and biological aspects, needs to be changed and expanded by adding new skills capable of sustaining actions focused on promoting health and based on the comprehensiveness of health care. The training of future dentists needs to consider improving diagnostic skills, and treating and preventing carious lesions, while taking into account the complexity of the microbiological and biological environment, without neglecting the critical socioeconomic influence on oral health.

Dentists graduating in this century must be aware of a variety of caries management strategies based on scientific evidence, which have been developed in the last years. Bearing in mind that Brazil has over 200 dental schools, a well-structured dental education system should deliver a high-quality and consistent education in cariology.

In 2010 the European Organization for Caries Research (ORCA) and the Association of Dental Education in Europe (ADEE) developed a European core curriculum in cariology for undergraduate dental students covering a wide range of important aspects of cariology. ${ }^{3}$ This document was based on the results of an ORCA/ADEE questionnaire on education in cariology, mailed to dental schools.

In Brazil, the ORCA/ADEE questionnaire was translated into Portuguese in 2011, and was used in conducting a survey. The questionnaire comprised 12 questions on how and when cariology has been taught in the country, and was sent to 203 Brazilian dental schools. The dean of each school was asked to forward the questionnaire to the main professor responsible for teacing cariology at the school.

A preliminary sample of 73 schools answered and returned the questionnaire. Most of the schools (63\%) stated that they had a specific cariology curriculum, taught mainly in three curricular units: Operative Dentistry (35\%), Preventive Dentistry (34\%) and Pediatric Dentistry (22\%). 
Only $15.1 \%$ of the schools stated having a specific discipline called "Cariology". Cariology topics were reported as taught in the second (61\%), third $(63 \%)$ and fourth $(50 \%)$ year of the undergraduate course. The second year was reported as the period when students mainly start pre-clinical activities, and the third year was when they start performing clinical procedures on patients. Most schools include the topics of dental erosion (66\%) and enamel defects (75\%) in their cariology training. This is in accordance with the way modern cariology is understood, i.e., including all aspects of hard tissue disorders/defects, such as dental erosion and non-erosive dental wear. Most schools describe using fluoride as a method of preventing dental erosion (73\%) and dental caries (86\%). Although high, these percentages are nevertheless a cause of concern, since $14 \%$ of schools do not teach that fluoride should be used as a method for controlling dental erosion and caries. The majority of schools surveyed taught most of the main cariology topics, but failed to include minimal intervention $(1.4 \%)$, caries lesions sealing $(2.7 \%)$, treatment decisions based on caries activity $(1.4 \%)$, restorative procedures $(1.4 \%)$, and ART $(1.4 \%)$ in their curricula.

Last, but no less importantly, it was found that

\section{References}

1. Brasil. Ministério da Saúde. Coordenação Geral de Saúde Bucal. Projeto SBBrasil 2010: pesquisa nacional de saúde bucal resultados principais. Brasília (DF): Ministério da Saúde; 2011 [cited 2013 Jan 15]. Available from: http://189.28.128.100/ dab/docs/geral/projeto_sb2010_relatorio_final.pdf. the majority of the responding dental schools (93\%) would support the development of an international cariology curriculum.

These preliminary results show that, although most of the dental schools assessed give special attention to some aspects of cariology, other important topics still need to be addressed. Furthermore, the teaching of cariology should also emphasize caries as a disease, whose prevention and treatment should focus on etiological factors such as dietary habits and oral hygiene instructions.

Finally, before establishing a set of national or international cariology curriculum guidelines, as suggested by the ORCA/ADEE cariology curriculum group, undergraduate teaching should be assessed in the whole country, taking into account Brazilian regional differences. With this in mind, further investigation of the remaining Brazilian dental schools is already under way, and a group discussion will be held at the Brazilian Meeting on Cariology Research (May 2013) with the aim of defining local strategies, to be presented at the upcoming ORCA Meeting (June 2013) in Liverpool, thus joining efforts with the ORCA/ADEE cariology curriculum group in setting further goals for this area of dentistry.

2. Mendes EV. A reforma sanitária e a educação odontológica. Cad Saude Publica. 1986 Out-Dec;2(4):533-52.

3. Schulte AG, Pitts NB. First consensus workshop on the development of a European curriculum in cariology. Eur J Dent Educ. 2011 Nov;15 Suppl 1:1-2. 